\title{
Aspectos discursivos da canção tropicalista "Eles": um posicionamento na interlingua(gem)
}

DOI: http://dx.doi.org/10.21165/el.v49i3.2575

\section{Bruno de Sousa Figueira'}

\section{Resumo}

Neste artigo, objetivamos analisar, sob a perspectiva teórica da Análise do Discurso, sobretudo a partir das noções teóricas propostas por Dominique Maingueneau em Discurso Literário (2006), aspectos da prática discursiva do movimento que ficou conhecido no campo literomusical brasileiro como Tropicália. Mais especificamente, analisaremos a canção "Eles", presente no álbum lançado em 1968 por Caetano Veloso. O objetivo fundamental deste trabalho é, a partir da exploração de uma semiose não verbal, isto é, dos aspectos musicais da canção, estender a noção de interlíngua, postulada por Maingueneau, para outras semioses - neste caso, utilizaremos o termo interlingua(gem).

Palavras-chave: interlíngua; interlingua(gem); código de linguagem; Tropicália.

1 Universidade Federal de Uberlândia (UFU), Uberlândia, Minas Gerais, Brasil; br.sousafigueira@gmail.com; https://orcid.org/0000-0002-4164-9645 


\title{
Discursive aspects of the tropicalist song "Eles": a positioning in the Interlanguage
}

\begin{abstract}
Drawing from the theoretical perspective of Discourse Analysis, especially from the theoretical notions proposed by Dominique Maingueneau in Literary Discourse (2006), in this paper we aim to analyze aspects of the discursive practice of the movement known in the Brazilian literary-musical field as Tropicália. More specifically, we will analyze the song "Eles", present in the album released in 1968 by Caetano Veloso. Through the exploration of a non-verbal semiosis, we set as the main objective of this work to extend the notion of interlingua (a postulate by Maingueneau that deals with linguistic matters) to other semiosis, that is, the musical aspects of the song - and, in this case, we will use the term interlanguage.
\end{abstract}

Keywords: interlingua; interlanguage; language code; Tropicália.

\section{Considerações iniciais}

O Tropicalismo foi um movimento que surgiu no interior do campo literomusical brasileiro², tendo sido influenciado por correntes artísticas de vanguarda, bem como pela cultura pop local e pela estrangeira. Liderado pelos compositores Caetano Veloso e Gilberto Gil e composto pelos artistas Torquato Neto, Capinan, Tom Zé, Os Mutantes, Rogério Duprat, Maria Bethânia, Gal Costa, Jorge Bem, Nara Leão, Sérgio Sampaio, entre outros, o grupo tropicalista buscou combinar as tradições da cultura brasileira com radicais inovações estéticas.

Conquanto as práticas tropicalistas tenham tido posição de destaque fundamentalmente no campo literomusical brasileiro, é relevante mencionar que as suas ideias influenciaram produções de outras naturezas. Nas artes plásticas, o grande nome influenciado pela Tropicália foi Hélio Oiticica. O movimento também influenciou o cinema nacional, principalmente o chamado Cinema novo de Glauber Rocha. Já no teatro, o destaque foi para as peças anárquicas de José Celso Martinez Corrêa.

Historicamente, conforme Favaretto (1996), o marco zero do Tropicalismo se deu a partir do lançamento das canções "Alegria, alegria" (Caetano Veloso) e "Domingo no Parque" (Gilberto Gil), em 1967, no III Festival da Música Popular Brasileira, da TV Record de São Paulo. Embora a Tropicália ainda não tivesse um status de movimento organizado na

2 Termo utilizado no estudo feito por Nelson Barros da Costa, intitulado Música popular, linguagem e sociedade: analisando o discurso literomusical brasileiro (2012). 
época do Festival, as canções de Caetano e Gil já indicavam os contornos do grupo, sobretudo por destoarem das demais canções tidas como pertencentes à MPB, pois as composições tropicalistas contavam com o uso de guitarras e sintetizadores, "arranjos performáticos" (que lançam mão de sons eletrônicos, sons futuristas, ruídos de pratos, gritos, cantos de pássaros e etc.). No entanto, foi somente com o lançamento, em 1968, do álbum Tropicália ou Panis et circenses (1968), que o Tropicalismo se despontou como um movimento organizado, que teve seu fim instituído no mesmo ano, apesar de continuar influenciando novas obras.

Tendo isso em vista, buscamos analisar, neste artigo, sob a perspectiva teórica da Análise do Discurso, sobretudo a partir das noções teóricas propostas por Dominique Maingueneau em Discurso Literário (2006), aspectos da prática discursiva do movimento Tropicalista. Mais especificamente, analisamos a canção "Eles", presente no álbum lançado em 1968 por um dos líderes do movimento, a saber, o cantor e compositor baiano Caetano Veloso.

O objetivo fundamental deste artigo é, a partir da exploração de uma semiose não verbal, isto é, dos aspectos musicais da canção, estender a noção de interlíngua, postulada por Maingueneau, para outras semioses - neste caso, cunhamos e mobilizamos ao longo do artigo o termo interlingua(gem), justamente porque a presente proposta visa deslocar o olhar de textos verbais (ou seja, língua em sentido stricto) para textos não verbais. Tendo isso em vista, encaminhamos a referida análise a partir da seguinte questão: como o fenômeno do posicionamento na interlíngua, observado por Dominique Maingueneau em textos de linguagem verbal, pode ser produtivo para a análise do nível musical de uma canção? Em outras palavras, ao considerar um texto de natureza não verbal, como é o caso do nosso objeto de estudo, de que maneira podemos pensar em posicionamento na interlingua(gem)? Ou ainda, os sujeitos de práticas discursivas de um movimento artístico-cultural, com produções em diversas semioses, inscrevem-se e posicionam-se em relação a que arquivo, de que natureza, com qual funcionamento?

A fim de investigar essas questões, então, partimos da hipótese de que o criador da canção constrói um código de linguagem específico, em função de um posicionamento na interlingua(gem), para constituir o nível musical de sua composição. Nesse sentido, supomos que a mobilização de um código de linguagem próprio, por exemplo: timbres, prosódias, melodias, instrumentos, técnicas de equalização e distorção, dentre outros aspectos constitutivos do nível musical de uma canção, legitima um posicionamento de determinado discurso no interior de um campo discursivo. No caso da canção "Eles", partimos da hipótese de que o criador em questão usa uma linguagem que lhe é própria, perante a um arquivo do campo, e assim legitima o posicionamento tropicalista, materializado pela semântica de mistura, no interior do campo literomusical brasileiro. 


\section{Fundamentação teórica}

Este trabalho tem como principal pilar teórico as reflexões e postulações que Dominique Maingueneau apresenta em Discurso literário (2006). Neste tópico, então, apresentaremos algumas noções dessa obra, pertinentes aos objetivos aqui elencados, além de uma breve referência à proposição teórica postulada por Costa (2012).

Nesse sentido, é preciso mencionar que, ainda que assumamos as postulações feitas por Dominique Maingueneau em Discurso Literário, buscaremos validá-las em um outro campo, a saber, o campo literomusical brasileiro, já que a Tropicália é um movimento que transita sobretudo no interior da MPB, ainda que extrapole para outros campos da arte em geral. Em função disso, considero para este trabalho um estudo feito por Nelson Barros da Costa, intitulado Música popular, linguagem e sociedade: analisando o discurso literomusical brasileiro (2012), cujo objetivo é demonstrar que a prática literomusical brasileira adquiriu em nosso país um estatuto de discurso constituinte e que, portanto, pode ser tratada com um estatuto semelhante ao do discurso literário. É sob esta perspectiva que trataremos o nosso objeto de estudo, considerando as especificidades de sua natureza, mas ao mesmo tempo assumindo, de forma análoga, os postulados teóricos de Maingueneau, conforme são apresentados em Discurso Literário.

Le discours littéraire, obra de Dominique Maingueneau publicada em 2005 e traduzida e lançada no Brasil em 2006 com o título de Discurso literário, é fruto de uma trajetória teórica que visa debater novas abordagens para o fato literário, dando luz a reflexões sobre como se constituiu o campo literário e suas particularidades, bem como a caminhos para possíveis análises de objetos desse campo.

Ainda no prefácio de Discurso literário, Maingueneau delimita o teor de sua reflexão, enfatizando que sua obra não se trata de um manual que objetiva resumir as realizações de uma disciplina estabelecida; diferentemente, afirma que o terreno que suas reflexões percorrem ainda está em constituição. Conforme o autor, "O discurso literário" mostra-se como um objeto ambíguo:

De um lado, designa em nossa sociedade um verdadeiro tipo de discurso, vinculado a um estatuto pragmático relativamente bem caracterizado; de outro, é um rótulo que não designa uma unidade estável, mas permite agrupar um conjunto de fenômenos que são parte de épocas e sociedades muito diversas entre si. (MAINGUENEAU, 2006, p. 9).

Consciente desse duplo estatuto é que Maingueneau propõe o que denomina Análise do discurso literário, considerando como corpus de análise a literatura ocidental, sobretudo a francesa, entre os séculos XVI e XX. De acordo com sua proposta teórico-metodológica, 
o objeto literário deve ser abordado como um evento enunciativo; nesse sentido, o autor afasta-se da tradicional perspectiva que se preocupa em olhar para o texto literário com a pretensão de responder à questão de como ir do texto ao contexto ou vice-versa. A proposta de Maingueneau passa a conceber, pois, o texto como uma forma de gestão do contexto.

\section{As noções de discurso constituinte e de paratopia}

Para refletir sobre uma análise do discurso literário, precisa-se entender o estatuto desse discurso - o seu modo de funcionamento, a sua natureza - que, para Dominique Maingueneau, deve ser compreendido como um discurso constituinte, assim como o religioso, o filosófico e o científico. Entender, pois, o que Maingueneau compreende por discursos constituintes é fundamental para o analista que irá lidar com análise de discurso de estatuto literário.

Conforme compreendido por Maingueneau (2006, p. 60), o discurso literário possui uma especificidade, ainda que não seja o único: "participa de um plano determinado da produção verbal, o dos discursos constituintes", que se propõem como discurso de Origem, que são validados por uma cena de enunciação que autoriza a si mesmos. Segundo o autor (2006, p. 60), "levar em conta as relações entre os vários 'discursos constituintes' e entre discursos constituintes e não-constituintes pode parecer uma custosa digressão, mas esse agir aumenta de maneira ponderável a inteligibilidade do fato literário".

Para falar em "discurso constituinte", Maingueneau (2006) parte da hipótese de que há um domínio específico que reúne alguns tipos de discurso, que possuem propriedades em comum relativas às suas condições de emergência, funcionamento e circulação. Em um primeiro momento, o discurso religioso, o científico, o filosófico e o literário podem parecer muito distintos entre si, mas são pertencentes a uma mesma categoria a partir da qual se pode agrupar tais discursos, cuja natureza "implica uma dada função (fundar e não ser fundado por outro discurso), certo recorte das situações de comunicação de uma sociedade (há lugares e gêneros vinculados a esses discursos constituintes) e certo número de invariantes enunciativas" (MAINGUENEAU, 2006, p. 61). Apesar de o discurso constituinte não possuir fronteiras fixas, assim como os demais discursos, ele conta com um número de invariantes, que permite, a partir de um programa de pesquisa, levantar questões novas a respeito do funcionamento do discurso.

De acordo com Maingueneau (2006, p. 68), é um aspecto dos discursos constituintes sua localidade paradoxal, pois sua enunciação se constitui da impossibilidade de atribuir a si um "lugar" verdadeiro, já que, para o autor: "aquele que enuncia no âmbito de um discurso constituinte não pode situar-se no exterior nem no interior da sociedade: está fadado a dotar sua obra do caráter radicalmente problemático de seu próprio pertencimento a essa sociedade". A esse caráter paradoxal, o autor irá denominar de paratopia, que 
não é a falta de um "lugar" próprio, mas advém da difícil negociação entre o lugar e o não-lugar, que emerge da própria impossibilidade de estabilizar-se. Ainda sobre esse aspecto, Maingueneau (2006, p. 68) afırma que: "sem localização, não há instituições que permitam legitimar e gerir a produção e o consumo de obras, mas sem deslocalização, não há verdadeira 'constituência"'. Então, o conceito de paratopia deságua em uma posição de fronteira para os discursos constituintes; o espaço paratópico que abarca o discurso constituinte não é fechado e facilmente delimitável, pois se constitui no recorte de espaços sociais.

Esse processo incide em três dimensões, segundo Maingueneau (2006, p. 70): i) no investimento de uma cenografia que faz do discurso um lugar de uma representação de sua própria enunciação; ii) no investimento de um código de linguagem que, a partir de um posicionamento na interlíngua, permite produzir um efeito prescritivo que resulta da conformidade entre o exercício da linguagem que o texto implica e o universo de sentido que ele manifesta; iii) no investimento de um ethos emerge do discurso uma voz que ativa o imaginário estereotípico de um corpo enunciante socialmente avaliado. Conforme o autor:

Essas noções estreitamente articuladas de cenografia, código de linguagem e ethos são uma maneira de abordar a questão do poder que a enunciação tem de suscitar a adesão ao inscrever seu destinatário numa cena de fala que é parte do universo de sentido que o discurso pretende promover. (MAINGUENEAU, 2006, p. 70).

Para introduzir sobre o que entende por paratopia, Maingueneau se baseia, como já mencionado, na característica de a literatura ser um discurso constituinte e, por isso, se valer de algumas instituições para legitimar e gerir sua produção e o consumo de obras. Entretanto, para garantir sua verdadeira constituência, ela não pode se filiar completamente a tais instituições, inserindo-se, dessa forma, em uma condição paradoxal: encontra-se nesta posição de fronteira entre a inscrição em seus funcionamentos tópicos (da sociedade) e o seu não pertencimento a nenhuma topia. Por isso, a literatura, como todo discurso constituinte, é tomada em um pertencimento impossível e, embora possa ser comparada a uma rede de lugares na sociedade, não pode criar raízes em nenhum território. Nas palavras de Maingueneau (2006, p. 92):

Enquanto discurso constituinte, a instituição literária não pode de fato pertencer plenamente ao espaço social, mantendo-se antes na fronteira entre a inscrição em seus funcionamentos tópicos e o abandono a forças que excedem por natureza toda economia humana. Isso obriga os processos criadores a alimentarse de lugares, grupos, comportamentos que são tomados num pertencimento impossível. 
De acordo com Maingueneau (2006, p. 95), para que uma obra releve de um lugar de paratopia, ela precisa irromper quando há tensões no campo literário, quando ela "só pode dizer alguma coisa sobre o mundo pondo em jogo em sua enunciação os problemas advindos da impossível inscrição social (na sociedade e no espaço literário) dessa mesma enunciação". O autor observa ainda que a paratopia é histórica e, assim, suas modalidades são variáveis de acordo com a época e a sociedade em questão.

Maingueneau também elucida que a paratopia só é motor da criação literária quando implica a figura singular do insustentável, que é o que torna essa criação necessária. Para o autor, é o criador da obra literária quem organiza seu modo de viver, tornando-se ele o responsável pela paratopia e, por consequência, pelo surgimento de sua obra. Nessa perspectiva, visões como a de que a obra é uma representação das experiências de vida do seu escritor, ou de que a obra é um universo independente de seu criador, precisam ser recusadas, já que, conforme Maingueneau (2006, p.119),

[...] a paratopia do escritor, na qualidade de condição da enunciação, também é seu produto; é por meio da paratopia que a obra pode vir à existência, mas é também essa paratopia que a obra deve construir em seu próprio desenvolvimento. $\mathrm{Na}$ qualidade de enunciação profundamente ameaçada, a literatura não pode dissociar seus conteúdos da legitimação do gesto que os propõe; a obra só pode configurar um mundo se este for dilacerado pela remissão ao espaço que torna possível sua própria enunciação.

Feito esse percurso, Maingueneau afırma que a paratopia só será de interesse para a AD quando tomada como condição e produto do processo criador. Sob essa perspectiva, apresentaremos a seguir a noção de código de linguagem (e posicionamento na interlíngua), uma das embreagens paratópicas que ancora o enunciado à enunciação e que se trata do conceito central deste estudo.

\section{Um posicionamento na interlíngua e a "língua literária"}

A língua também é parte essencial do movimento pelo qual uma obra se institui; ela se relaciona ao posicionamento, ainda que para isso ocorra um deslocamento da problemática da língua para a interlíngua.

Segundo o autor, o criador não situa sua obra num gênero, tampouco numa língua. Em outras palavras, uma língua não é utilizada em uma obra pela mera razão de ser a língua materna do autor. O que ocorre é que o escritor, justamente por ser escritor, é obrigado a escolher uma língua por meio da qual inscreve a sua obra em um posicionamento, língua que não pode ser a sua. Sobre isso, Maingueneau (2006, p. 180) detalha: "o trabalho de escrita consiste sempre em transformar nossa própria língua em língua estrangeira, em convocar outra língua na língua, línguas outras, língua do outro, outra língua". 
O criador, em sua ação de escrita, atua sempre na quebra, na falta, na não-coincidência, na clivagem. Conforme uma máxima de Mallarmé (apud MAINGUENEAU, 2006, p. 181), "falta às línguas imperfeitas, porque várias, a suprema: sendo pensar escrever sem acessórios, sem cochicho, permanecendo a imortal palavra que, se assim não fosse, encontraria, por um caráter único, materialmente a verdade".

Para se negar que o escritor, por meio de sua obra, escreve em sua língua materna, devese se distanciar das representações impostas pela estética romântica, que considera as obras como pertencentes, de forma orgânica, a uma língua. Na verdade, segundo Maingueneau (2006, p. 181), o escritor se reapropria de sua língua materna em função de seu trabalho criador, assim, "o escritor não fabrica seu estilo a partir de sua língua, mas antes impõe a si, quando deseja produzir literatura, uma língua e códigos coletivos apropriados a gêneros de texto determinados". Nesse caso, há usos específicos de uma "língua literária" que competem à literatura e, nesse sentido, não há conflito "entre enunciação literária e submissão a um ritual linguístico preestabelecido, sendo a cisão entre o escritor e 'sua' língua de certo modo codificada" (MAINGUENEAU, 2006, p. 182).

Desse modo, o escritor não enfrenta uma língua específica na sua criação, ao contrário, lida com uma interação de línguas e seus usos; a tal interação Maingueneau se refere como interlíngua. Em síntese, a interlíngua diz respeito às

[...] relações que entretêm, numa dada conjuntura, as variedades da mesma língua, mas também entre essa língua e as outras, passadas ou contemporâneas. É a partir do jogo dessa heteroglossia profunda, dessa forma de "dialogismo" (Bakhtin), que se pode instituir uma obra. (MAINGUENEAU, 2006, p. 182).

Nesse sentido, de acordo com o estado do campo literário e a posição que ele ocupa, o criador negocia por meio da interlíngua um código de linguagem que lhe é próprio. A essa noção associam-se a ideia de "código" como um sistema de regras e signos que permite uma comunicação, e a ideia de "código" como um conjunto de prescrições: "por definição, o uso da língua que a obra implica se apresenta como a maneira pela qual se tem de enunciar, por ser esta a única maneira compatível com o universo que ela instaura" (MAINGUENEAU, 2006, p. 182).

O autor pondera também que mesmo quando a obra parece usar uma língua considerada "comum", existe um embate com a alteridade da linguagem, que se vincula a um determinado posicionamento no campo literário. Nesse sentido, não podemos pensar que a literatura tenha alguma relação natural com o uso linguístico, ou seja, não podemos ter a ilusão de que haja escritores que, ao utilizarem "a língua comum", possam ser considerados neutros. Maingueneau (2006, p. 188) cita o exemplo dos escritores clássicos, que parecem escrever "o" francês comum da elite culta, mas "inscrevem-se na realidade num código particular, aquele em que, sob a égide da mundanidade e do centralismo monárquico, se associam desde o século XVII à clareza e à elegância". 
Longe de ser neutro, o embate criativo do escritor com a interlíngua pode operar-se sem diferença aparente, como se a obra, em sua própria enunciação, se sobressaísse à própria língua que apresenta. Para exemplificar esse caso, o autor apresenta o poeta judeu Paul Celan, que se exprime em alemão mesmo após o Holocausto, isto é, apresenta sua obra na língua de seus perseguidores, fazendo com que a obra, em sua enunciação, se destaque à língua.

É necessário destacar ainda a relação entre a interlíngua e o intertexto, já que entre eles há em ação uma continuidade natural. Segundo Maingueneau (2006, p. 194), o que ocorre é um tipo de "atração" que liga o código de linguagem de um escritor à utopia de outra língua ou de outro uso da língua "na medida em que estes já tenham sido investidos pela literatura".

Em linhas gerais, o que Maingueneau leva em conta ao tratar deste tópico é que o escritor, numa relação singular com a interlíngua, legitima o posicionamento de sua própria obra. Nesse sentido, o criador não se vale meramente de uma língua, mas realiza a interação da obra com possíveis "línguas" para instituir-se em um posicionamento.

Tendo em vista essa fundamentação teórica, apresentamos a seguir um estudo que aborda as características gerais do movimento tropicalista, principalmente dos álbuns de Caetano, Gil e Tom Zé. Delinear essas questões é um movimento fundamental a este trabalho, visto que esta caracterização sustentará a nossa análise e, por conseguinte, as nossas hipóteses.

\section{Aspectos gerais da semântica tropicalista}

Nesta seção do artigo, apresentaremos pontos fundamentais da obra Frio tropical: tropicalismo e a canção popular, de autoria de Carlos Pires (2012), fruto de sua dissertação de mestrado, Canção popular e processo social no tropicalismo, defendida em 2011 na Universidade de São Paulo (USP).

Em sua obra, Pires (2012) investiga aspectos dos três principais discos tropicalistas: Caetano Veloso (1968), Gilberto Gil (1968) e Grande Liquidação (1968). Esses LPs, além de serem representativos do posicionamento tropicalista, possuem um efeito de fundação do movimento. Por essa razão, este tópico do artigo se faz importante, visto que as análises empreendidas por Pires nos oferecem subsídios para lançar hipóteses a respeito da semântica do discurso tropicalista.

Nesse viés, no capítulo introdutório de seu trabalho, Pires $(2012$, p. 2) demonstra que os três discos, encabeçados, respectivamente, por Caetano, Gil e Tom zé, surgiram em um contexto no qual o Brasil ainda não havia consolidado o processo de integração de seus meios culturais. Conforme o autor, 
[...] esses LPs mantêm um diálogo estreito e ambivalente com essa integração e profissionalização dos meios culturais. É possível perceber já em suas capas certa atitude diferenciada que buscavam forjar. Os artistas, que antes eram destaques, nesses três álbuns rivalizam com um fundo colorido em um procedimento de colagem: Caetano Veloso aparece em uma foto com a expressão séria, com o rosto a meia luz, em uma moldura oval apoiada no braço de uma mulher em uma espécie de paraíso pop pintado com cores fortes; Gilberto Gil está vestido com um fardão semelhante ao da academia brasileira de letras em um fundo verde e amarelo com detalhes vermelhos onde ainda estão duas pequenas fotos em que o artista posa com uma farda militar e com um volante na mão de óculos escuro guiando um automóvel invisível; o rosto de Tom Zé aparece com a expressão séria em uma televisão preto e branco disposta em um plano recuado em relação a um cenário urbano popular pintado, também, com cores fortes. As capas, com essas dissociações ostensivas entre figura e fundo, fotografia e desenho, aludem aos procedimentos compositivos das canções. (PIRES, 2012, p. 2).

Pires (2012, p. 2-3) menciona ainda, na introdução de seu trabalho, o seu pioneirismo, afirmando que, apesar da forte valorização do tropicalismo na história recente do país, o seu estudo é o primeiro que olha para esses três LPs de forma sistemática. Conforme o autor, os discos analisados apresentam, nos diferentes níveis da composição musical, "as contradições de um acalentado projeto nacional e popular em vias de se realizar, ou se desintegrar, em chave industrial rebaixada para as massas".

Centrando-se em uma síntese das características que recortamos da obra de Pires a respeito dos três primeiros álbuns tropicalistas, podemos supor que o movimento tem, em sua estética, um forte apelo à experiência popular vinculada à profissionalização e sofisticação dos meios culturais, sendo a mistura um dos principais aspectos de sua semântica. De modo mais específico, estamos supondo como "mistura" um traço semântico de oposição aos movimentos musicais considerados mais puristas, como a Bossa $\mathrm{Nova}^{3}$ e o Samba, que propunham uma ideia de música nacional sem a interferência direta do cenário musical internacional.

A seguir, apresentamos uma breve análise da canção "Eles", presente no álbum tropicalista de Caetano Veloso, de 1968. Conforme mencionamos anteriormente, o nosso objetivo a partir desta análise é o de demonstrar que também há a construção de um código de linguagem específico, em função de um posicionamento na interlingua(gem), na criação de semioses de outras naturezas, não tão somente no nível linguístico - neste caso, a musical.

3 A respeito da problemática em torno do que é fazer música nacional no campo literomusical brasileiro desse período, consultar a dissertação de mestrado Transgressão e conservadorismo na prática discursiva da Jovem Guarda, defendida por Heloisa M. Mendes, em 2009, na Universidade Federal de Uberlândia. 
Antes, porém, é necessário mencionar que, tendo em vista que a presente proposição busca estender o conceito de interlíngua, desenvolvido por Maingueneau (2006), para interlingua(gem), o gesto analítico apresentado a seguir se concentra somente nos aspectos da música em sentido stricto sensu, ou seja, sem uma abordagem sobre a letra da canção. Essa opção, além de ser justificada em função do objetivo deste trabalho, fundamenta-se em Maingueneau (2008, p. 137-138), segundo o qual, embora haja uma primazia do nível linguístico sobre as demais semioses, "o pertencimento a uma mesma prática discursiva de objetos derivados de domínios semióticos diferentes exprime-se em termos de conformidade a um mesmo sistema de restrições semânticas". Isto é, todas as produções pertencentes a uma mesma prática discursiva são submetidas ao mesmo filtro semântico, "às mesmas escansões históricas, às mesmas restrições temáticas etc.", sendo justificável e profícuo analisar somente o nível não-linguístico da canção, já que o sistema de restrições semânticas incide igualmente sobre todas as semioses produzidas sob um mesmo discurso.

\section{A identidade nacional-universal em “Eles"}

A canção, presente no álbum de Caetano, composta conjuntamente com o seu parceiro Gilberto Gil, é acompanhada na gravação pela banda Os Mutantes, e tem uma introdução estranha aos ouvidos dos que estavam acostumados com uma musicalidade nacionalregional, como os registros do Samba, da Bossa Nova ou das Canções de Protesto, que não aceitavam - pelo menos em seu posicionamento discursivo - os elementos da música pop estrangeira. O prelúdio da canção de Veloso é executado por um dedilhar em um instrumento de cordas numa escala que parte das notas mais graves e vai em direção às mais agudas, construindo um clima de suspense que logo é rompido por um solo acelerado do mesmo instrumento de cordas, que já pode ser identificado como um sitar, acompanhado por um instrumento de percussão, a tabla.

Ambos os instrumentos são tradicionais na Índia. O sitar, confundido popularmente com a cítara, é da família dos cordofones, isto é, suas cordas se estendem junto a uma caixa de ressonância e produzem um som metálico, algo parecido com a guitarra. Já a tabla é uma percussão dividida em dois tambores, um agudo chamado daya e um grave chamado baya, comumente utilizado na Índia em músicas devocionais ou meditativas. A construção de um código de linguagem típico do oriente já demarcaria o posicionamento tropicalista por uma música nacional-universal, que privilegia a mistura, mas essa hipótese ganha mais força quando buscamos outros intertextos, como é o caso das produções da banda inglesa The Beatles, que também sofreram influência da música indiana.

O $7^{0}$ álbum dos Beatles, intitulado Revolver (1966), marca a adesão da banda inglesa ao chamado rock psicodélico e experimental, e apresenta uma faixa que também foi influenciada pela musicalidade oriental e indiana, a saber, a canção "Love you to", composta pelo beatle George Harrison. Na ficha técnica da canção, do mesmo modo 
como na composição tropicalista, são listados instrumentos indianos como a tabla e o sitar, que podem ser identificados logo na introdução da música. Tendo isso em vista, é possível supor fortemente que a canção "Eles" mobiliza um registro musical específico em função de um posicionamento na interlingua(gem). Isto é, o criador em questão constitui uma linguagem que lhe é própria, perante a um arquivo do campo, e assim legitima o posicionamento tropicalista, materializado pela semântica de mistura, no interior do campo literomusical brasileiro.

A introdução à lá Beatles em "Eles" é concluída por um fade-out (quando o volume do áudio é gradualmente diminuído até o silêncio) e a canção toma imediatamente outra forma rítmica, indiciando que a construção de um código específico, alusivo a uma musicalidade pop-internacional, não exclui os aspectos da música regional brasileira e nem abandona a semântica de mistura. Isso porque a canção passa a ser acompanhada por chocalhos e por uma tessitura vocal que alude ao ritmo da literatura de cordel - a uma prosódia típica do repente nordestino. Nesse sentido, a canção se constrói por meio de um esquema de rimas que parece que o cantor tem um "canto-falado", característica tradicional da música popular dessa região do Brasil. Conforme Santos (2015, p. 65), "a instrumentação concilia a cítara com o coco e a entonação do cantor permite relacionar a canção com as rimas da literatura de cordel, imprimindo no seu canto o que Tatit compreende como figurativização, dado o evidente aspecto de canto-falado, de oralidade".

Ao mesmo tempo em que há essa intertextualidade rítmica com a musicalidade regional do nordeste, a canção é acompanhada por um contrabaixo e uma guitarra com distorção e sofre variavelmente uma certa "rasura" causada pelo órgão elétrico, aspectos que podem inferir em um posicionamento em relação a um arquivo da música pop de estética experimental, que tem como característica inserir ruídos na canção.

Logo após serem entoados os primeiros versos da música, com a marcação rítmica pela rima e as rasuras provocadas pelo órgão, é possível perceber um solo improvisado da guitarra elétrica (depois de ser cantado o verso "alegres ou tristes, são todos felizes durante o natal"). Esse improviso da guitarra com distorção mobiliza um registro típico do blues e do jazz norte-americano, o que legitima, mais uma vez, a semântica do posicionamento tropicalista de música nacional-universal. Segundo Santos (2015, p. 65), neste mesmo trecho da canção ainda é possível perceber certo deboche do vocal, a partir de um tom de voz que parece ser interferido por um riso:

[...] o deboche apresenta-se tanto pelas intervenções mais vigorosas dos instrumentos elétricos, com primazia para o som do órgão, quanto pela dicção do narrador, cuja escuta atenta demonstra como a sua entonação realiza-se com riso, deboche, dado o aumento da tessitura melódica ao cantar a palavra natal 
Esse tom debochado, satírico e irônico é uma forte característica do posicionamento tropicalista. Segundo Dunn (2007), em artigo escrito para o site Tropicália,

[...] suas principais canções-manifestos eram alegóricas, apresentando os relatos pesarosos da história nacional, muitas vezes sob o disfarce da ironia e da sátira. Suas performances mais importantes, no entanto, apontavam em uma nova direção, informada pela contracultura internacional e carregada de exuberância catártica em face da repressão crescente.

Esse apontamento para uma contracultura internacional não vinha à tona apenas pelo deboche na entonação da voz, mas por outros elementos "estranhos" que compunham as canções, característica marcante na música psicodélica. Em "Eles", por exemplo, podemos perceber algumas colagens de ruídos durante a execução da música. Depois de ser cantado o verso que diz "eles sempre falam no dia de amanhã", é perceptível ao fundo um barulho que foi recortado, e não produzido por algum instrumentista; o mesmo se repete quando outro ruído é inserido após o trecho que diz "eles amam os filhos no dia de amanhã". Outro estranhamento é provocado por uma pausa incomum na linha do tempo da canção, a saber, entre a execução das expressões "tomam táxi" e "no dia de amanhã" e, logo em seguida, ouve-se, mais uma vez, outro ruído insólito.

O mesmo modus operandi visto até aqui é seguido no restante da canção: a marcação da música regional pelo chocalho e pela prosódia característica do repente; as ranhuras na melodia provocadas pelo órgão elétrico; os solos improvisados da guitarra distorcida; a entonação de riso e a colagem de ruídos. Em síntese, é colocada em cena na canção uma confluência de registros musicais, alusivos a diferentes intertextos presentes no campo que, suponhamos, constrói um código de linguagem próprio que legitima a semântica de mistura nacional-universal do posicionamento da Tropicália. Isto é, uma forma de se posicionar na interlingua(gem).

Antes da conclusão da canção, porém, outra "estranheza" experimental é provocada ao interlocutor: algumas vozes distorcidas disputam a cena e, logo em seguida, Caetano profere: "Os Mutantes são demais". O fato de a banda Os Mutantes ter acompanhado musicalmente a execução da canção também é uma maneira de posicionamento na interlingua(gem); a parceira com o trio psicodélico-tropicalista formado por Arnaldo Baptista, Rita Lee e Sérgio Dias reitera o posicionamento de mistura e põe em relevo, mais uma vez, o projeto estético da Tropicália. Sintetizando os elementos que são mobilizados em "Eles", e reforçando as nossas hipóteses, Pires (2012, p. 114) afirma:

Ao assumir uma composição mais livre - ou mais presa, dependendo do ponto de vista - o autor, como indicam a vinheta Beatles e a saudação final aos Mutantes "Os Mutantes são demais", parece, novamente, querer colocar em xeque a linha dura do samba. Isso ao mesmo tempo em que põe na estrutura rítmica uma 
síncope, que dá um travo particular na dinâmica - um dos centros da força do rock - com uma pausa em relação ao tempo quadrado do contrabaixo, insinuando um samba justaposto à improvisação criada.

\section{Considerações finais}

Tendo em vista as nossas hipóteses e a análise apresentada no tópico anterior, consideramos que, assim como o literato, o criador de uma canção também constrói um código de linguagem específico, em função de um posicionamento na interlingua(gem), para constituir o nível musical de sua composição.

De acordo com o que foi analisado, o timbre, a prosódia, o instrumental, as colagens de ruídos, as distorções e o backing vocal utilizados na execução da canção de Caetano Veloso indiciam a semântica de mistura da Tropicália, legitimando, desse modo, o posicionamento do movimento, no interior do campo literomusical brasileiro.

Portanto, supomos que, a partir da canção analisada, pudemos demonstrar que a questão central deste trabalho é relevante e produtiva. Isto é, é possível pensar em posicionamento na "interlíngua" - ou melhor, na interlingua(gem) - quando lidamos com textos de natureza não verbal. Além disso, consideramos que, ao expandir o conceito postulado por Maingueneau, abrimos inúmeras possibilidades de pesquisas no campo da AD, especialmente estudos que analisam corpora intersemióticos.

\section{REFERÊNCIAS}

COSTA, N. B. da. Música popular, linguagem e sociedade: analisando o discurso literomusical brasileiro. Curitiba: Appris, 2012.

DUNN, C. Tropicália: modernidade, alegoria e contracultura. Tropicália, 2007. Disponível em: http://tropicalia.com.br/v1/site/internas/visestr_1.php. Acesso em: 10 jan. 2019.

FAVARETTO, C. Tropicália, alegoria, alegria. São Paulo: Ateliê Editorial, 1996.

MAINGUENEAU, D. Gênese dos discursos. São Paulo: Parábola, 2008.

MAINGUENEAU, D. Discurso literário. São Paulo: Contexto, 2006.

MELLO, Z. H. de; SEVERIANO, J. A canção no tempo. v. 2. São Paulo. Editora 34 Ltda, 1998. 
MENDES, H. M. M. Transgressão e conservadorismo na prática discursiva da Jovem Guarda. 2009. Dissertação (Mestrado em Estudos Linguísticos) - Instituto de Letras, Universidade Federal de Uberlândia, Uberlândia, 2009.

PIRES, C. Frio tropical: tropicalismo e a canção popular. São Paulo: Alameda, 2012. 